\title{
Monseñor Romero, conflictividad eclesial y carisma ministerial
}

\author{
Martin Maier, \\ Stimmen der Zeit, \\ München.
}

"Sentir con la Iglesia". Este es el lema que escogí Monseñor Romero en su ordenación episcopal, el 21 de junio de 1970. La fidelidad a la Iglesia y al papa fue una constante en su vida. Sin embargo, después de su profunda transformación, que lo llevó a convertirse en un profético defensor de los pobres, su "sentir con la iglesia" quedó expuesto a pruebas dolorosas. Tuvo que enfrentar resistencia y persecución no sólo de parte del poder político y económico, sino también de parte del Vaticano y de los demás obispos salvadoreños - con la excepción de Mons. Rivera-, quienes lo trataron con total incomprensión y férrea oposición.

Ricardo Urioste, quien como vicario general durante su arzobispado estuvo muy cercano a él, insiste en que sufría mucho más por los ataques que venían del interior de la Iglesia que por los que venían del exterior. Las acusaciones y las amenazas de destitución como arzobispo lo pusieron en un conflicto existencial entre su fidelidad a la jerarquía de la Iglesia, en Roma, y su fidelidad a los pobres y oprimidos de su pueblo. También su "sentir con la Iglesia" se transformó profundamente a lo largo de su vida. Durante largo tiempo, comprendió a la Iglesia según la eclesiología preconciliar, con el papa y la jerarquía, pero la fue comprendiendo cada vez más como el pueblo de Dios entre los pobres. "Sentir con la Iglesia" llegó a significar "sentir con los pobres". La tragedia fue que su dedicación a quienes, en forma preferencial, hacen presente a Jesucristo en la historia lo llevó a un conflicto dramático con el nuncio y con el Vaticano. Monseñor Romero no busc6, en modo alguno, el conflicto. Sin embargo, por fidelidad al evangelio y a su conciencia, en algunas ocasiones, no le quedó otra opción que "resistir a la jerarquía eclesiástica cara a cara", como Pablo lo hizo con Pedro...

Dada su notable sencillez, Monseñor Romero muy posiblemente hubiese rechazado que lo tomasen por un místico. Pero es cierto que, en el misterio de Dios, 
se le reveló, y -como a Jesús - en los "niños" (ver Mt 11,25), y aprendió a ver la cruz de Cristo, en el sufrimiento de su pueblo. De ahí que su religiosidad bien puede ser comprendida como una "mística" del pueblo crucificado.

Igual que hubiese rechazado que lo tuvieran por místico, hubiese rechazado también que lo tuviesen por "crítico de la Iglesia". Es cierto que la critic6, pero siempre lo hizo desde una profunda identificación y en conexión con su sufrimiento con la Iglesia. Eso es lo que resuena en su lema, "sentir con la Iglesia". Este tiene su origen en la "reglas para el sentido verdadero que en la Iglesia militante tenemos que tener" del libro de Ejercicios de san Ignacio de Loyola. Con la palabra "sentir", Ignacio señala la capacidad espiritual-mística de percibir lo que acaece de modo inmediato "entre el Criador y su criatura". Este "sentir" lo relaciona también muy conscientemente con la Iglesia institucional jerárquica.

En la primera parte de este artículo analizaremos la tensión entre mística personal y eclesialidad, en Ignacio de Loyola. Dentro de este marco, analizaremos, en una segunda parte, los conflictos de Monseñor Romero con la Iglesia oficial. Finalmente, esbozaremos un nuevo paradigma del ejercicio del ministerio episcopal, desde la conexión entre carisma místico y ministerio jerárquico, en Monseñor Romero.

\section{El "sentir con la iglesia" en Ignacio de Loyola}

Durante toda su vida, la espiritualidad ignaciana fue muy importante para Monseñor Romero. El seminario interdiocesano de San Salvador, donde entró en 1937, fue dirigido por los jesuitas hasta el año 1972. También el Colegio Plo Latinoamericano y la Universidad Gregoriana, en Roma, donde estudio, desde 1938 hasta 1943, son instituciones jesuitas, que tanto espiritual como teológicamente influyeron de modo decidido en Monseñor Romero. Aquí conocí Romero los Ejercicios Espirituales de Ignacio de Loyola y su espiritualidad se convirtió en su fuente espiritual más importante. Con frecuencia, se retiró a hacer los ejercicios espirituales, la última vez unas semanas antes de su muerte. Al principio de 1950, incluso hizo los ejercicios de treinta días, bajo la guía del padre jesuita Miguel Elizondo.

La finalidad de los Ejercicios es, en ambiente de oración e intenso silencio, enrumbar la vida, según la voluntad de Dios. Para conseguirlo es fundamental contemplar los pasajes del evangelio sobre la vida de Jesús, y así acercarse, cada vez más, a Jesús. Este proceso acaece, según la nota introductoria I4 del libro de los Ejercicios", "inmediatamente entre el Criador y su criatura". Pues bien, Ignacio describe ese conocimiento interno espiritual con el verbo "sentir".

I. Citamos los ejercicios según Obras completas de S. Ignacio de Loyola, Biblioteca de Autores Cristianos, Madrid 1952. Los números entre paréntesis indican los números del libro de los Ejercicios. 
La segunda nota da instrucciones básicas para la contemplación de los pasajes de la Escritura, sobre las que se basa todo el proceso de los ejercicios, como hemos dicho. En el texto original aparece, de nuevo, el verbo "sentir" dos veces: es decisivo, en la contemplación de las Escrituras, encontrar algo "que haga un poco más declarar o sentir la historia" (2). Al final de esa nota viene la frase que puede ser la regla básica válida para toda la vida espiritual: "porque no el mucho saber harta y sarisface al ánima, mas el sentir y gustar las cosas intemamente" (2). Más importante que la comprensión racional de las cosas espirituales es, entonces, "su sentir intemamente".

También las mociones de consolación y de desolación, que tienen un significado central en el proceso espiritual de los Ejercicios, son descritas como "sentir": ambas son "sentidas" (ver 62). Ignacio las describe también con el sustantivo "sentimiento espiritual" (62). Propone la indiferencia en "los tiempos para hacer elección" - las diversas maneras de tomar una decisión de vida - "para seguir aquello que sintiere más en gloria y alabanza de Dios nuestro Señor y salvación de mi ánima (179). Asimismo, la finalidad de los ejercicios, es decir, el deseo de parecerse más a Jesús, está relacionada con el "sentir" (109). Y en otro contexto, en muchas cartas de Ignacio, una forma de saludo final va unida al deseo de que "su santísima voluntad sintamos y aquella enteramente cumplamos".

Fridolin Marxer ha mostrado de manera convincente, en su investigación sobre Los sentidos espirituales internos, en la mística ignaciana ${ }^{2}$, cuál es el significado central del "sentir": "El verbo 'sentir' tan usado por san Ignacio ... señala una forma de experiencia total, una percepción o bien un experimentar en lo profundo del alma, en el que toda la persona toma parte ${ }^{3}$. Marxer también ha señalado que con el "sentir" está ligado cierto elemento iluminativo, lo que puede aclarar por qué Ignacio, en España, y después, durante su tiempo de estudios, en París, tuvo dificultades con la inquisición eclesiástica. Se le acusaba de ser un "alumbrado". Los "alumbrados" españoles, al principio del siglo XVI, se remitían a una iluminación interna, producida por el Espíritu Santo, con independencia de la Iglesia, lo cual alarmó a los guardianes eclesiásticos de la fe.

Con ese trasfondo, Ignacio agregó a sus ejercicios las "reglas para el sentido verdadero que en la Iglesia tenemos que tener", en las cuales busca poner en relación el "sentir" y la Iglesia institucional, jerárquica". Jerónimo Nadal, de la primera generación de jesuitas, conocido por ser uno de los mejores directores de los ejercicios, caracteriza la relación dialéctica de espíritu e Iglesia en Ignacio

2. Cfr. Fridolin Manxer, Die inneren geistlichen Sinne. Ein Beitrag zur Deutung der ignatianischen Mystik, Freiburg, 1963, p. 155.

3. Ibid., p. 157.

4. Cfr. Joaquín Salaverri, "Motivación histórica y significación teológica del ignaciano 'sentir con la Iglesia'", Estudios Eclesiasticos 31 (1957), 139-171. 
como "sentimientos muy vivos de los misterios divinos y de la Iglesia"s. En los mismos términos se describe aquí mística y eclesialidad. Según Hugo Rahner, en ello estriba la dialéctica de la elección en los ejercicios: "estar abiertos para aquel llamado único de Dios, y con el mismo ordo escuchar la voz de la Iglesia jerárquica" 6 .

El fundamento teológico para el "sentir con la Iglesia" lo ofrece Ignacio, en su décima tercera regla: "creyendo que entre Cristo nuestro Señor, esposo, y la Iglesia su esposa, es el mismo espiritu que nos gobiema y rige para salud de nuestras ánimas, porque por el mismo Spíritu y Señor nuestro, que dio los diez Mandamientos, es regida y gobernada nuestra sancta madre Iglesia" (365). Ya algunos años antes, en una carta a la religiosa Teresa Rejadella, donde le aclaraba cómo entendía la dirección espiritual, Ignacio habla adelantado esta explicación del sentir con la iglesia. Todavía de manera más explícita que en los ejercicios se pone aquí en relación la experiencia personal mística con la Iglesia institucional:

Acaece que muchas veces el Señor nuestro mueve y fuerza nuestra ánima a una operación o otra abriendo nuestra ánima; es a saber, hablando dentro de ella sin ruido alguno de voces, alzando toda a su divino amor, y nosotros y su sentido, aunque quisiesemos, no pudiendo resistir, y el sentido suyo que tomamos, necesario es conformamos con los mandamientos, preceptos de la Iglesia y obediencia de nuestros mayores, y lleno de toda humildad, porque el mismo espíritu divino es en todo?.

Todo lo dicho es verdad, pero hay que añadir que con ello, de ninguna manera, están excluidos los conflictos entre los entendimientos y las decisiones, conseguidos en la búsqueda personal de la voluntad de Dios, y la Iglesia oficial. Raymund Schwager en su libro La dramática concepción de la Iglesia en Ignacio de Loyola, lo ha mostrado con muchos ejemplos de la vida de san Ignacio.

$Y$ ahora volvemos a nuestro tema. También Monseñor Romero fue fiel al "sentir con la Iglesia", pero su relación con la dirección de la Iglesia jerárquica, en Roma, durante sus tres años como arzobispo de San Salvador, fue dramática. Lo cual es más asombroso, puesto que antes había mostrado una obediencia casi temerosa frente a todas las directrices de la curia romana. Es lo que vamos a ver en la segunda parte de este artículo.

\section{El conflicto de Monseñor Romero con la Iglesia institucional}

El asesinato del padre Rutilio Grande, el 12 de marzo de 1977, fue un acontecimiento clave para la profunda transformación de Monseñor Romero. Su su-

5. Ver Hugo Rahner, Ignatius von Loyola als Mensch und Theologe, Freiburg. 1964, p. 372.

6. Ibid., p. 377.

7. Obras completas de S. Ignacio de Loyola, p. 663. 
cesor Arturo Rivera y Damas interpreta esta experiencia tan decisiva para Monseñor con las siguientes palabras: "Un mártir dio vida a otro mártir. Delante del cadáver del Padre Rutilio Grande, Monseñor Romero, en su vigésimo día de arzobispo, sintió el llamado de Cristo para vencer su natural timidez humana y llenarse de la intrepidez del apostol. Desde aquel momento, Monseñor Romero dejó las tierras paganas de Tiro y Sidón, y marchó libremente hacia Jerusalén"§g.

Fruto de la transformación de Monseñor Romero fue una nueva unidad, nunca antes existente, en la Iglesia de base. Pero, en cambio, sí se produjo una división en la jerarquía. Del diario de Monseñor Romero se desprende que lo que más le hizo sufrir fue la enconada oposición de los demás obispos y el nuncio. Sólo el obispo Arturo Rivera y Damas lo apoyó.

\subsection{Conflictos con el nuncio}

La primera confrontación con la Iglesia institucional se dio en el contexto de su decisión - con ocasión del entierro de Rutilio Grande y sus dos acompañantes - de celebrar una misa única en la catedral metropolitana, y mostrar así, desde un punto de vista pastoral, la situación de emergencia que atravesaba el país. Durante mucho tiempo, había tratado el asunto con los sacerdotes de la arquidiócesis, y al final, la gran mayoría se había decantado por la "misa única". Pero Monseñor Romero no hab́a calculado bien la oposición del nuncio apostólico Emmanuelle Gerada, quien se opuso por todos los medios a dicha decisión. Su argumentación la baso en motivos pastorales, de derecho canónico y políticos. No se podía aceptar, pastoralmente, el dejar a muchas comunidades sin misa en domingo. El secretario del nuncio intentó convencer a Monseñor Romero de las incongruencias canónicas, y lo trató personalmente sin ningún respeto, como a un aprendiz. El argumento político del nuncio era que el estado de excepción que había impuesto el gobierno prohibía, entre otras cosas, concentraciones masivas. En contra, Monseñor Romero argumentó diciendo que en los partidos de fútbol en los estadios se reunían muchos aficionados y que eso era tolerado por el gobiemo. En realidad, los motivos del nuncio y su secretario eran sólo aparentes. Lo que no querían era que se produjeran tensiones con el gobiemo, aun cuando éste era represivo.

Monseñor Romero se mantuvo furme en su decisión, la cual, aun desde el punto de vista canónico, era de su entera competencia. La misa única tuvo lugar con una afluencia de más de 100 mil personas. Sin embargo, su hasta entonces buena relación con el nuncio, comenz 6 a deteriorarse. Las líneas de conflicto estaban trazadas. Monseñor Romero sabía que tenía el apoyo de la gran mayoría de su clero y de los creyentes. Por el contrario, la posición del gobiemo y de la oligarquía estaba representada, de facto, por el nuncio y los obispos Pedro Amoldo Aparicio

8. Jesús Delgado, Óscar A. Romero, Biografia, San Salvador, 1990, p. 3. 
de San Vicente, Benjamín Barrera de Santa Ana, con su auxiliar Marco René Revelo, y Eduardo Álvarez de San Miguel. Monseñor Romero tenía que partir del hecho de que, canalizadas por el nuncio y el gobiemo, estaban llegando noticias negativas a Roma sobre su inesperado quehacer pastoral. De este modo, decidió viajar el 26 de marzo a Roma para defender, en persona, su posición ante al papa y la curia.

Hasta entonces, sus relaciones con los dicasterios vaticanos habían estado libres de problemas. Incluso, dos años antes, Monseñor Romero había sido nombrado consultor de la Comisión Pontificia para América Latina. En noviembre de 1975, redactó para esta Comisión un memorandum confidencial con el título "Tres factores del movimiento sacerdotal político en El Salvador". En la primera parte, analizaba críticamente las actividades de los jesuitas, en El Salvador. En la segunda parte, criticaba al Secretariado Social Interdiocesano y a la Comisión Justicia y Paz que, a sus ojos, eran demasiado críticas del gobiemo. En la tercera parte, se mencionaba a "grupos de sacerdotes, religiosos y cristianos comprometidos de todas las diócesis", que actuaban políticamente y se servían de análisis marxistas. Según su criterio, estos grupos se habían apartado de la tarea propia de la Iglesia y se movían en una peligrosa proximidad a las ideas revolucionarias.

Estas posturas de Monseñor Romero tuvieron mucho que ver, seguramente, con su nombramiento como arzobispo, sobre lo cual su predecesor Luis Chávez y Gonź́lez se quejó amargamente: "Es curioso que la Santa Sede no me haya hecho caso con Monseñor Rivera, que siempre fue mi candidato y lo sabían. Cuarenta años de arzobispo y no tuvieron en cuenta mi opinión"s.

En su primera visita al Vaticano, estuvo en la Congregación de los Obispos, con cuyo prefecto, el Cardenal Sebastiano Baggio, tuvo un áspero diálogo. Aparentemente, en Roma, habían caído en la cuenta que su cálculo con el nombramiento de Monseñor Romero como arzobispo, había fallado. El 30 de marzo de 1977, tuvo un encuentro a solas con el papa Pablo VI. Le entregó una foto de Rutilio Grande, que aquél bendijo. Pablo VI dio un espaldarazo a Monseñor Romero y señaló con énfasis que la conducción de la arquidiócesis era responsabilidad sólo de él. Positivo fue el encuentro con la Secretaría de Estado, el último día de su estancia en Roma, con el arzobispo Agostino Casaroli, en ese entonces secretario del Consejo para las Cuestiones Públicas de la Iglesia. Desde Roma, Monseñor Romero escribió una carta conciliatoria al nuncio con la esperanza de tener de nuevo una buena relación. Pero no iba a tener efecto.

El secuestro y asesinato del Ministro de Relaciones Exteriores Mauricio Borgonovo Pohl por un grupo guerrillero de izquierda, agudizó la situación política, en El Salvador. El día de su entierro, 11 de mayo de 1978, Alfonso Navarro fue el segundo sacerdote en ser asesinado. El 13 de mayo tuvo lugar una reunión

9. Marra López Vigil, Piezas para un retrato, San Salvador, 1993, p. 74. 
extraordinaria de la conferencia episcopal con el nuncio. Se trató sobre todo la cuestión de la unidad entre los obispos, en su posición frente al gobierno y sobre los sacerdotes "pro marxistas". Algunos obispos tampoco estaban de acuerdo con la "misa única". Ya se vislumbraba la división en la conferencia.

\subsection{División en la conferencia episcopal}

La división se hizo evidente en el encuentro bianual regular de la conferencia episcopal del 11 al 13 de julio de 1977. Los obispos Álvarez y Barrera, en los crecientes conflictos sociales y políticos, representaban la posición del gobiemo represivo. Por su parte, Monseñor Romero se refirió, en su pastoral, al Concilio Vaticano II, la encíclica Evangelii Nuntiandi del papa Pablo VI y a los documentos de la Conferencia Episcopal Latinoamericana de Medellín. A pesar de ello, lo presionaban, cada vez con mayor frecuencia, a que justificase sus actuaciones.

A finales de junio de 1977, Monseñor Romero envió una carta confidencial al cardenal Baggio. Escribía: "Creo haber meditado ante el Señor y haber consultado suficientemente mis decisiones"10. A la base de su actuación estaba - según la espiritualidad ignaciana - la búsqueda personal de la voluntad de Dios, y cambién el esfuerzo de discemir sus decisiones, en diálogo con otros. Mencionaba también la abundante solidaridad de dentro y fuera del país, y del continente, como señal de aprobación de su quehacer pastoral.

Sin embargo, para el caso de que, a pesar de que tenía tranquila la conciencia, la Santa Sede juzgara falsas sus actuaciones pastorales, se declaró dispuesto a escuchar las quejas e incluso a depositar la dirección de la arquidiócesis en otras manos. Sobre las dificultades con el nuncio Gerada escribió:

Con tristeza debo manifestar a Vuestra Eminencia que, en estas circunstancias tan dolorosas y difíciles para mí, no he contado con el apoyo de S. E. acerca de mis actuaciones; al contrario, en ciertos momentos he sentido muy dura su presión contra mis decisiones. Al analizar esta rara actitud de $\mathrm{S}$. E. he concluido que $\mathrm{S}$. E. vive muy alejado de los problemas de nuestro clero y de nuestro humilde pueblo y en él predominan las informaciones y presiones del Cardenal Casariego", de los políticos, de los diplomáticos y de la clase adinerada de las colonias elegantes. [...] Es de justicia confesar que actualmente S. E. no goza de simpatías en el clero ni en nuestro pueblo por esas preferencias ${ }^{12}$.

10. James R. Brockman, La palabra queda: vida de Mons. Oscar A. Romero, San Salvador, 1985, p. 103.

11. El cardenal Mario Casariego (1909-1983) era arzobispo de Guatemala y representaba posiciones tanto reaccionarias como peligrosas, en el conflicto interno guatemalteco y salvadoreño.

12. Ibid.p. $104 \mathrm{~s}$. 
En consecuencia, Monseñor Romero dedujo "mantener nuestra acción pastoral más autónoma de la actividad diplomática de la Nunciatura"13.

La transformación que se había realizado en Monseñor Romero queda muy clara cuando se comparan estas declaraciones con la posición que él representó algunos años antes como secretario de la conferencia episcopal, cuando los seminaristas renunciaron a tomar parte en la liturgia de aniversario de la coronación del papa, debido a la posición progobiemista del nuncio. Juan Hemández Pico lo recuerda así: "Fue el fin del mundo. Le habían tocado al papa y al nuncio y habían irrespetado a la jerarquía de la Iglesia, iqué más!"'14.

La división al interior de la Iglesia se acentuó en octubre de 1977. El obispo auxiliar Marco René Revelo, en un sínodo de obispos, en Roma, declaró, entre otras, que los catequistas en el campo salvadoreño eran indoctrinados por marxistas, lo que produjo las delicias de los medios de comunicación masiva, manejados por la oligarquía. Monseñor Romero escribió a Revelo en Roma: "Creo un deber de sinceridad fratema comunicarle que sus palabras en el sínodo de obispos, publicadas aqui con la acostumbrada bulla, han desconcertado a los sacerdotes y al pueblo, que cada vez es más consciente de nuestra línea pastoral"'ls.

En El Salvador, como en otros países de América Latina, la acusación de ser marxista o comunista podía significar una sentencia de muerte. Desde el punto de vista de la oligarquía y del ejército, cualquier medio estaba permitido para exterminar "la peste del comunismo". Por eso, fue devastador el haber evocado el fantasma de marxismo al interior de la Iglesia. Con eso, se había confrontado Monseñor Romero, ya al final de una reunión de la conferencia episcopal, como lo escribe en su Diario:

La reunión de los obispos en la Nunciatura confirmó la división que existe entre nosotros. Únicamente se acordó denunciar oficialmente el asesinato del padre Macías. El señor Nuncio se ofreció también a apoyar esa denuncia en su proxima visita al Presidente de la República. Pero cuando se trató de ver las causas, se dejo llevar la junta por los prejuicios de una infiltración marxista dentro de la Iglesia y no fue posible sacar de alli todos los prejuicios, a pesar de que traté de explicar que la situación de persecución de muchos sacerdotes es por querer ser fieles al espíritu del Vaticano Segundo, traducido a América Latina por Medellin y por Puebla. Muy poco se comprende esto y más bien se echa la culpa a una instrumentalización del marxismo al que está sirviendo la Iglesia, según ellos. Ofrecí a Dios esta prueba de paciencia, ya que a mí se me culpo, en gran parte, del mal que pasa en el país y en nuestra Iglesia (Diario p. 239) ${ }^{16}$.

13. Ibrd., p. 105.

14. Vigil, op. cit., p. 47.

15. Brockman, op. cit., p. 135.

16. Citamos el Diario y las homilías de Mons. Romero según han sido recogidos en Colección homillas y Diario de Mons. Óscar Arnulfo Romero, 9 volúmenes, San 
Un ejemplo concreto de cómo los obispos no acuerpaban a sus sacerdotes es el obispo Álvarez. Miguel Ventura era párroco de Osicala. Fue apresado y torturado durante varios días, en las bartolinas de la policía, en Gotera. El obispo Álvarez sólo dijo estas increíbles palabras para aclarar lo ocurrido: "Es que al padre Miguel lo torturaron en cuanto hombre, pero no en cuanto sacerdote"17. Por eso, no veía ningún motivo para protestar públicamente. Monseñor Romero, por el contrario, se refirió a este caso, en su homilía del 6 de noviembre de 1977, como un ejemplo de la continuada persecución a la Iglesia.

La confrontación con el nuncio se agudizó, cuando en marzo de 1978, un grupo de sacerdotes redactó una carta al diplomático vaticano, firmada por más de 300 sacerdotes de un total de 1,125 sacerdotes y religiosas del país. Empezaba con estas palabras: "Después de serena reflexión a la luz del Evangelio, llegamos a la convicción de que Jesús, Señor de la Historia, nos urge a denunciar aquellos aspectos de su actividad que significan grave escándalo para el Pueblo de Dios y que son destructivos para la Iglesia y su misión evangelizadora"18. Como "anti-evangélicas" fueron señaladas sus diferencias con Monseñor Romero y su apoyo a un "gobiemo represivo e injusto".

La carta fue publicada por la prensa. El 3 de abril, se reunió de urgencia la conferencia episcopal. Sin tener en cuenta a Monseñor Romero y a Monseñor Rivera, los demás obispos habían preparado un documento, en el cual criticaban la carta durísimamente. A los autores se les acusó de falta grave en contra de la Santa Sede. Monseñor Romero, por su parte, propuso algo que debiera ser normal para lograr un entendimiento: no se debe acusar a los sacerdotes sin antes haberlos escuchado. Y luego hizo una distinción muy interesante: "Yo distinguí entre la Santa Sede, principalmente la figura del Papa con el cual estos sacerdotes se sienten unidos por la fe, $y$ la figura del Nuncio que representa al Papa y que no siempre lo representa nítidamente". (Diario, p. 5). Además, le parecía "que publicar este documento era fomentar una división entre los obispos", ya que él no estaba dispuesto a fumarla. Sobre el resultado de la reunión, anotó en su diario:

El documento quedó aprobado y yo fui objeto de muchas acusaciones falsas de parte de los obispos. Se me dijo que yo tenía una predicación subversiva, violenta; que mis sacerdotes provocaban entre los campesinos el ambiente de violencia y que no nos quejáramos de los atropellos que las autoridades andaban haciendo. Se acusaba a la Arquidiócesis de interferir en las otras diócesis provocando la división de los sacerdotes y el malestar pastoral de otras diócesis. Se acusaba al Arzobispado de sembrar la confusión en el Seminario y

Salvador, 2000. En las citas de las homilías, los números romanos indican el tomo y los arábigos, la página.

17. Vigil, op. cir., p. 168.

18. Brockman, op. cit., p. 156. 
que era urgente que saliera del edificio de San José de la Montaña el Arzobispado de San Salvador. Y otra serie de acusaciones calumniosas y falsas a las cuales preferí no contestar. Ha sido un día amargado por esta circunstancia y lamentando que la división en el episcopado se aumenta con este paso, que me apareció poco prudente (Diario, p. 6).

Naturalmente, este conflicto no pasó inadvertido en el Vaticano. Monseñor Romero recibió del cardenal Baggio una carta, fechada el 16 de junio de 1978, donde lo invitaba a una "fratema y amistosa conversación". Por segunda vez, como arzobispo, dirigió sus pasos hacia Roma. En la Congregación de los Obispos le indicaron conversar, en primer lugar, con Monseñor Miguel Buro, quien, sin embargo, apenas lo dejó hablar. Monseñor Romero escribe sobre ello en su diario: "Hemos notado en su mentalidad una serie de conceptos y prejuicios, que nos han dejado muy poca esperanza para comprender la pastoral que está llevando nuestra Arquidiócesis" (Diario, p. 40). El encuentro del 20 de junio, que había sido anunciado como fraterno y amistoso con el cardenal Baggio, se desarrolló de manera muy desagradable para Monseñor Romero. Baggio externó su desilusión sobre la conducta de Monseñor Romero, lo que él compartía con muchas respetables personas y también con los otros obispos salvadoreños. La confrontación con el nuncio la señaló como "un escándalo casi irreparable"1". Además, el cardenal criticó que el mismo Monseñor Romero hablaba de su cambio como de una "conversión".

Monseñor Romero redactó, al final de este encuentro con Baggio, un memorándum de nueve páginas, dirigido al cardenal. Sobre la "acusación" de su conversión dice: "Lo que sucedió en mi vida sacerdotal, he tratado de explicármelo como una evolución de mi mismo deseo que siempre he tenido de ser fiel a lo que Dios me pide; y si antes di la impresión de ser más 'prudente' y 'espiritual' era porque así creía sinceramente que respondía al Evangelio, pues las circunstancias de mi ministerio no se habían mostrado tan exigentes de una fortaleza pastoral que en conciencia creo que se me pedía en las circunstancias en que asumí el arzobispado"20. Monseñor Romero relacionó, entonces, su cambio personal con su fidelidad a la voluntad de Dios. También aquí se refleja su arraigo en la espiritualidad de los Ejercicios.

Sobre su relación con el obispo auxiliar Marco René Revelo, en quien había perdido toda confianza, escribió: "Con franqueza fratemal, debo expresar a V. E. que la misma $S$. Sede y mis hermanos Obispos han falseado las bases de esa confianza, cuando él mismo confiesa -y V. E. me lo confirmó- que su nombramiento ha sido 'para frenarme' y los Sres. Nuncio y Obispos utilizan ese mismo encargo para fomentar al antagonismo que destruye una relación cordial"21.

19. Ibid., p. 184.

20. lbíd., p. 182.

21. Ibrd., p. 184. 
Monseñor Romero mencionó también los peligros que nacían de la falta de unidad de los obispos. Así, por ejemplo, el mayor Roberto D'Aubuisson, principal responsable de la persecución contra la Iglesia y del asesinato del mismo Monseñor Romero, afirmaba: "Estos curas han armado una cosa que se llama Iglesia Popular, que no es nuestra lglesia del Vaticano, la Iglesia que dirige el Papa, la Iglesia de la que nosotros somos creyentes"22.

Esta división de la conferencia episcopal era un reflejo de la división de toda la sociedad salvadoreña y de la misma Iglesia. Debilitaba la posición de la Iglesia y confundía a los creyentes. Monseñor Romero se refirió a ello, en su cuarta y última carta pastoral. Señalaba esta división como la expresión más visible del pecado en la Iglesia. Como arzobispo, hizo un acto de contricción por ese pecado, y a los creyentes les pidió perdón $n^{23}$.

Nunca se escuchó algo semejante a los otros obispos. Al contrario. Poco tiempo después en una homilía, el obispo Aparicio asumió totalmente la visión de la extrema derecha sobre la persecución contra la Iglesia. Esta homilía fue publicada en una página completa, en los periódicos de mayor circulación. En el Diario de Monseñor Romero se encuentra la siguiente anotación, fechada el 13 de septiembre de 1979: "Es una tremenda condenación de los sacerdotes, a los cuales él dice que no puede defender y casi los acusa y los expone a un asesinato; diciendo que los sacerdotes que fueron matados, fueron purgados por la misma izquierda y que hay sacerdotes comprometidos con la izquierda que no pueden retroceder sin que los maten. Nos hemos reunido con otros sacerdotes que están muy indignados de esta acusación tan peligrosa" (Diario, p. 258).

La ruptura que atravesaba la Iglesia salvadoreña dividió también a la Iglesia de todo el subcontinente latinoamericano. Esto se hizo evidente en la III Conferencia General del Episcopado Latinoamericano, reunido en Puebla, a inicios de 1979. Monseñor Romero participó en la conferencia, no como delegado de la conferencia episcopal salvadoreña, sino como miembro de la Comisión Pontificia para América Latina. En Puebla, encontró a obispos como el ecuatoriano Leónidas Proaño, el mexicano Sergio Méndez Arceo, así como a los cardenales brasileños Aloísio Lorscheider y Paulo Evaristo Arns, quienes, al igual que él, optaban decididamente por los pobres. Se encontró, sin embargo, con la animadversión del obispo Alfonso López Trujillo. en ese entonces Secretario General de la Conferencia Episcopal Latinoamericana. López Trujillo era el vocero de aquellos obispos que, en Puebla, querían una condena de la teología de la liberación, un control centralizado sobre las comunidades eclesiales de base y el debilitamiento de la opción por los pobres.

22. Vigil, op. cit., p. 156.

23. La voz de los sin voz. La palabra viva de Monseñor Romero, Introducción, comentarios y selección de textos de Jon Sobrino. Ignacio Martín-Baró y Rodolfo Cardenal, San Salvador, 1980, pp. 136s. 
En total, a Monseñor Romero le fueron enviados cuatro "visitadores apost6licos", es decir, controladores vaticanos, durante sus tres años como arzobispo. Uno de ellos, al final de 1978, fue el obispo argentino, y más tarde cardenal, Antonio Quarracino. Éste recomend6 nombrar un "Administrador Apostólico Sede Plena", para con ello, quitarle, de facto, el poder como arzobispo. Monseñor Romero dijo, al final de esta visita: "Si no me quieren así, que me quiten de arzobispo y me manden de cura a una parroquia. Pero yo no voy a cambiar por eso mis palabras, porque hablo según mi conciencia"24. De manera semejante se había expresado ya en el memorando mencionado al cardenal Baggio: "Si es para bien de la Iglesia, con el mayor gusto entregaré a otras manos este difícil gobiemo de la Arquidiócesis. Pero mientras la tengo bajo mi responsabilidad, sólo trataré de agradar al Señor y servir a su Iglesia y a su pueblo, de acuerdo con mi conciencia a la luz del Evangelio y del Magisterio"2s. Con ello hemos llegado al punto más álgido en el conflicto de Monseñor Romero con la dirección oficial de la Iglesia: ¿puede exigir Roma a los obispos que, por "obediencia", actúen de manera contraria a su conciencia?

Todavia de forma más clara se expresó Monseñor, en un encuentro con el provincial jesuita César Jerez: "En dado caso, prefiero que me quiten de arzobispo e irme con la cabeza en alto antes que entregar la Iglesia a los poderes de este mundo"26. Jerez no deja lugar a dudas: con los "poderes de este mundo" no se refería al gobierno de El Salvador, sino al gobierno de la Iglesia, los poderes del cardenal Sebastiano Baggio: "Parecía decidido a no achicarse ante ellos"27.

\section{3. ¿De qué lado está Roma?}

En el contexto de sus dificultades con el nuncio y el obispo auxiliar Revelo, Monseñor Romero escribió una carta al papa. Por causa de esa carta, un sacerdote fue contactado por un miembro de la embajada de Estados Unidos, en San Salvador. ¿Cómo llegó una copia de esa carta a la embajada estadounidense? Esta pregunta preocupó profundamente a Monseñor Romero. Existían dos posibilidades: o había una fuga de información en la curia arzobispal, pero entonces la copia de la carta no podía llevar la firma de Monseñor Romero; o una copia de la carta original firmada fue enviada por el Vaticano a la embajada. Las investigaciones dieron cono resultado que era una copia de la carta firmada, por lo que tuvo que ser enviada por el Vaticano. Monseñor Romero se preguntó compungido: "Pero entones, $i$ Roma de qué lado está?"2".

24. Vigil, op. cit., p. 221.

25. Brockman, op. cir., p. 186.

26. Vigil, op. cil., p. 147.

27. Ibid.

28. Ibld., p. 219. 
De qué manera los círculos vaticanos intentaban hacer política contra Monseñor Romero resultó tambien claro a principios de 1978 con motivo de la siguiente situación. La Universidad de Georgetown, de los jesuitas en Washington, decidió conferirle un doctorado honoris causa como signo de apoyo intemacional, por su entrega a la justicia y a los derechos humanos. De manera formal, la universidad le informó con dos meses de anticipación al delegado apostólico, en Washington. Sin embargo, dos semanas antes de la fecha fijada, el Vaticano expresó su desacuerdo. El cardenal Gabriel Garrone, prefecto de la Congregación para la Educación Católica, escribió al superior general de los jesuitas, pidiéndole intentar impedir la ceremonia. Sin embargo, los jesuitas estuvieron de acuerdo con la Universidad de Georgetown en que ninguno de los planes debía ser cambiado. Por eso, el Vaticano ya no insistí más. El 14 de febrero de 1978, en la catedral de San Salvador, le fue conferido a Monseñor Romero, con la participación de muchas personas sencillas, el doctorado honoris causa. El nuncio y tres obispos estuvieron ausentes de la ceremonia. El cardenal Baggio, más tarde, calificó este doctorado como una "trampa política" 29.

A principios de 1980, el gobierno de Estados Unidos anunció el aumento de la ayuda militar al gobiemo salvadoreño, lo cual no era más que echarle más leña al fuego del conflicto, el cual ya se asemejaba a una guerra civil. Monseñor Romero redact 6 una carta al entonces presidente estadounidense Jimmy Carter, la cual leyó durante la misa del 17 de febrero de 1980: "La contribución de su Gobiemo en lugar de favorecer una mayor justicia y paz en El Salvador agudizará sin duda la injusticia y la represión en contra del pueblo organizado"30. Advirtí6 a Carter que la intromisión de Estados Unidos, en El Salvador, lastimaba el derecho de autodeterminación, tal como lo hablan recalcado expresamente los obispos latinoamericanos, en su conferencia de Puebla. Menos de veinticuatro horas después, ya había llegado una carta del Departamento de Estado de Washington a la Secretaría de Estado del Vaticano. A través de la curia general de los jesuitas, Monseñor Romero se enteró del "revuelo" que su homilía, y en especial, su carta al presidente Carter, había causado en Roma.

\subsection{La relación de Monseñor Romero con los papas}

Aun en los momentos más duros, la fidelidad de Monseñor Romero al papa fue inamovible. En su homilía del 9 de abril de 1978 aclaro: "Quiero hacer profesión de fe solemne en este momento de mi adhesión al Santo Padre. El Papa ha sido siempre para mí una iluminación y pienso morir fiel a él. También quiero profesar mi comunión con el cuerpo episcopal del mundo" ( $N$, p. 124). En otra homilía, definió al papa como "el corazón de la Iglesia" (VI, p. 36). Refiriéndose

29. Brockman, op. cir., p. 187.

30. Ibid., p. 319. 
a la conferencia episcopal de Puebla, su encuentro con el sucesor de Pedro es lo más importante $(V I$, p. 86). Dijo que él era el más necesitado del papa y que cada semana seguía sus declaraciones $(V I$, p. 238).

Para él, su encuentro personal con el papa Pablo VI, en su visita a Roma, en junio de 1978, fue de suma importancia. Recordándolo, anotó en su Diario las siguientes frases del papa: “Comprendo su difícil trabajo. Es un trabajo que puede ser no comprendido, necesita tener mucha paciencia y mucha fortaleza. Ya sé que no todos piensan como usted, es difícil en las circunstancias de su país tener esa unanimidad de pensamiento, sin embargo, proceda con ánimo, con paciencia, con fuerza, con esperanza" (Diario, p. 42). Abandonó Roma con mucha gratitud: "Siento nostalgia, dejar a Roma. Roma es hogar para el que tiene fe y tiene sentido de Iglesia. Roma es la patria de todos los cristianos. Allá está el Papa, el verdadero padre de todos. Lo he sentido tan cerca, voy tan agradecido con él" En la siguiente visita a Roma, visitó la tumba de Pablo VI, de quien le impresionó su modestia, "el nuevo estilo de sencillez y humildad en el servicio de la Iglesia"32, que había acuñado Pablo VI.

Al ser elegido Papa, el 16 de octubre de 1978, Karol Wojtila, Monseñor Romero externó sus dudas sobre si sería capaz de comprender la realidad de los países latinoamericanos, desde su trasfondo polaco: "El viene de Polonia, viene del otro lado... Y a saber si le da por respaldar al gobierno de Estados Unidos. Para combatir al comunismo, pues. Creyendo que así defiende la fe, que así le conviene la Iglesia..." ${ }^{33}$. Por ello es que Monseñor Romero consideró importante informarle de primera mano lo más pronto posible sobre la situación de El Salvador. Ya el 7 de noviembre, envió a Juan Pablo II una carta de seis páginas sobre la situación de la arquidiócesis. Escribe:

Desde el principio de mi ministerio en la arquidiócesis, creí en conciencia que Dios me pedía y me daba una fortaleza pastoral especial que contrastaba con mi temperamento y mis inclinaciones "conservadoras". Creí un deber colocarme decididamente a la defensa de mi Iglesia y, desde la Iglesia, al lado de mi pueblo tan oprimido y atropellado. En todas mis actuaciones, he pedido mucha luz al Espíritu Santo para que no me apartara del evangelio, ni de las pautas del Concilio Vaticano II, ni de los documentos autorizados de Medellín. Especialmente, ha sido para mí una norma providencial la exhortación Evangelii Nuntiandi ${ }^{34}$.

En abril de 1979, emprendió una nueva visita a Roma para presentarse personalmente al nuevo papa. Aunque él ya hacía tiempo que había solicitado una

31. Ibid., p. 189.

32. $L$ a voz de los $\sin v o z$, p. 127.

33. Vigil, op. cit., pp. $217 \mathrm{~s}$.

34. Brockman, op. cit., p. 209. 
audiencia, fue detenido por la burocracia de la curia y citado siempre para otro día. Aparentemente, había fuerzas en el Vaticano que no deseaban que se encontrara con el papa. En su diario se refleja su creciente desesperación sobre este tratamiento.

No ha dejado de preocuparme mucho esta actitud para con un pastor de una diócesis, cuando he pedido con tiempo la audiencia y se va dejando al tiempo la respuesta; hasta temo que no se me vaya a conceder, porque hay muchos obispos en visita ad limina y hay también otros criterios para dar preferencia a otras solicitudes. Lo he dejado todo en las manos de Dios diciéndole que, de mi parte, he hecho todo lo posible, que, a pesar de todo, creo y amo a la Santa Iglesia y seré siempre fiel, con su gracia, a la Santa Sede, al magisterio del Papa y que comprendo la parte humana, limitada, defectuosa de su Santa Iglesia, que siempre es el instrumento de salvación de la humanidad y a la cual quiero servir sin ninguna reserva (Diario, pp. 158s).

Finalmente, en una audiencia general, pidio personalmente al papa un encuentro. El papa estuvo de acuerdo. Pero el encuentro no fue muy feliz. Al parecer, Juan Pablo II habia sido informado parcial y negativamente sobre Monseñor Romero. Su más importante encargo fue que debía esforzarse en tener una mejor relación con el gobierno de su país. En su Diario, Monseñor anotó con cuidado que su primera impresión no fue del todo satisfactoria. En el viaje de retorno, en una escala en Madrid, con lágrimas en los ojos, le contó a una periodista conocida este primer infeliz encuentro ${ }^{35}$.

El segundo y último encuentro de Monseñor Romero con el papa Juan Pablo II, el 30 de enero de 1980, transcurrió de manera más alentadora. Con antelación, Pedro Arrupe, superior general de los jesuitas, había manifestado al papa que la pastoral de Monseñor Romero y sus homilías eran positivas. Sobre esto escribió en su Diario: "Lo cual parece que ha influido mucho en los juicios del Santo Padre. Así, se notaba también que le sorprendió cuando el padre Arrupe le comunicó que ya eran seis los sacerdotes asesinados en el país. Daba la impresión de que al Papa no se le transmite una información objetiva de la situación de la Iglesia en nuestro país" (Diario, p. 257).

Juan Pablo II lo alentó a continuar la "defensa de la justicia social" y a proseguir en la línea de la "opción preferencial por los pobres". No obstante, el papa le avisó de los "peligros de una infiltración ideológica del marxismo", que podría "socavar la fe cristiana en el pueblo". Por su parte, Monseñor Romero manifestó que atendía al "equilibrio" necesario. "Pero - añadió-, también le dije al Papa que existe un anticomunismo que no está para defender la religión, sino el capital; el anticomunismo de derechas" (Diario, p. 376).

35. Cfr. Vigil, op. cir., p. 285. 
Es notable que el mismo papa Juan Pablo Il cambió su opinión sobre Monse ñor Romero. Así, en su primera visita a El Salvador, en 1983, insistió, en contr de los planes oficiales, en orar en la tumba de Monseñor Romero. Públicament lo alabó como un celoso pastor, que dio su vida por amor a Dios y al servicio d sus hernanos. También en su segunda visita a El Salvador, en 1996, visitó s' tumba. De manera expresa, Juan Pablo II insistió en nombrar a Monseñor Ro mero, en la conmemoración de los mártires cristianos, el Año del Jubileo $200 C$ en el Coliseo Romano ${ }^{36}$.

\subsection{La eclesiología de Monseñor Romero}

La presentación anterior de los conflictos del arzobispo Romero con la Igle sia institucional deja claro que no puede ser considerado como un crítico de ésti en sentido normal. Su crítica a la Iglesia tiene un carácter indirecto: se vuelv crítico y sin ambivalencias solamente cuando cree que ésta no es fiel a su mar dato original, que es ser servidora de la humanidad y sobre todo de los pobre: Desde esta perspectiva y desde esta comprensión de Iglesia, podemos desartc Ilar, de manera resumida, los elementos esenciales de esta crítica.

Monseñor Romero encarnó en su vida la profunda transformación en la col cepción de la Iglesia del Concilio Vaticano II, que pasa de ser una societc perfecta, cerrada y jerárquica, a ser pueblo de Dios e Iglesia de los pobres. Un de sus primeros textos que han quedado impresos, la homilía de Réquiem de : fallecido amigo el obispo auxiliar Rafael Valladares, el 2 de septiembre de 196 reflejaba todavía una concepción de Iglesia triunfalista y completamente sobr natura ${ }^{37}$. Sin embargo, en los años siguientes, hizo suya la nueva autocomprel sión conciliar de la Iglesia como pueblo de Dios, que peregrina en la historia, servicio del mundo y de la humanidad. La Iglesia del concilio se entiende con sacramento de salvación y de unidad entre la humanidad, lo que también inclu: la dimensión histónca y social. En consecuencia Monseñor Romero estaba en co tra de "una Iglesia meramente espiritualista, una Iglesia de sacramentos, de rezc pero sin compromisos sociales, sin compromisos con la historia" (I-II, p. 61).

Una característica esencial de la Iglesia para Monseñor Romero es su acerc miento a los pobres: "Sólo puede ser verdadera Iglesia la Iglesia que se convie te y se compromete con el pueblo sufrido y pobre" (VIII, p. 228). En relaci estrecha con esto está la tarea profética de la Iglesia de anunciar la verdad denunciar la injusticia (VI, p. 323). Al hacerlo, cae en contradicción con 1 poderes de este mundo y es perseguida. Pero la persecución, por causa de

36. Información obtenida del cardenal Walter Kasper.

37. Las cuatro páginas impresas de esta homilía están unidas con un fastener y hasta dla de hoy no han sido tomadas en cuenta en ninguna publicación sobre Monsei Romero. Fueron puestas a disposición del redactor por Gloria de García Prieto. 
justicia, es para Monseñor Romero un signo de que la Iglesia está cumpliendo su misión. De esta manera, agregó la persecución a las notas clásicas de la verdadera Iglesia: "La persecución es una nota característica de la autenticidad de la Iglesia; que una Iglesia que no sufre persecución, sino que está disfrutando los privilegios y el apoyo de las cosas de la tierra, itenga miedo!; no es la verdadera Iglesia de Jesucristo" ( $V I$, p. 192). Aplica a la Iglesia el pasaje del evangelio: es mejor perder la vida que ganar todo el mundo (VI, p. 323).

Para Monseñor Romero, la Iglesia siempre es una Iglesia de pecadores, entre los que él se considera uno de los primeros ( $V$, p. 30). En su segunda carta pastoral, habló de "lo que ella misma puede tener de pecado"’38, por lo que necesita conversión. El pecado principal de la Iglesia consiste en la contradicción entre lo que enseña y lo que hace $(V$, p. 279). Una tentación fundarnental es estar en contubernio con los poderosos. Más bien, la Iglesia tiene que estar dispuesta a perder todos sus privilegios: "No es un prestigio para la Iglesia estar bien con los poderosos. Este es el prestigio de la Iglesia: sentir que los pobres la sienten como suya, sentir que la Iglesia vive una dimensión en la tierra llamando a todos, también a los ricos, a convertirse y salvarse desde el mundo de los pobres, porque ellos son únicamente los bienaventurados" (VIII, p. 235).

Aquí tocamos el núcleo de la crítica eclesial de Monseñor Romero: la Iglesia falla en su misión cuando trata de estar fuera de la historia, y cuando se pone al lado de los poderosos, cuando no toma en serio, para sí misma, el misterio pascual de la muerte y la resurrección. Por el contrario, la Iglesia cumple su misión construyendo el reino de Dios, el cual según la primera bienaventuranza, pertenece a los pobres. Consecuentemente, sentir con la Iglesia significa, para Monseñor Romero, sentir cada vez más con los pobres. En ellos se encuentra al Cristo que vive presente en la historia. Esto lo desarrolló Monseñor Romero en su segunda carta pastoral sobre "La Iglesia como cuerpo de Cristo en la historia".

Ser fiel a Jesucristo significa para la Iglesia fidelidad a los pobres, un continuado sumergirse en el mundo de los pobres y en la solidaridad con su destino. Con ellos, la Iglesia realiza en su propio cuerpo el misterio de cruz y resurrección. Esto fue el tema en la primera carta pastoral "La Iglesia de la pascua". Central en la mística de Monseñor Romero es aprender a ver en el sufrimiento de los pobres al siervo de Dios sufriente del profeta Isaías y la cruz de Cristo. De esta manera, califica al pueblo sufriente y oprimido de El Salvador como un "pueblo crucificado". AsI como la cruz de Jesús es el centro de la fe cristiana, para Monseñor Romero, el pueblo crucificado está en el centro de su fe y de su espiritualidad. En él, la cruz de Cristo se vuelve presente aquí y ahora. Sin embargo, la cruz no sólo simboliza el pecado y el sufrimiento, sino que también es símbolo

38. Brockman, op. cir., pp. $115 \mathrm{~s}$. 
de redención y salvación. Monseñor Romero está convencido de que también el pueblo crucificado transmite luz y salvación. El hace un llamado a la conversión a todos aquellos que son responsables de su sufrimiento. Al igual que el siervo de Dios del profeta lsaías, se convierte en luz para los pueblos.

\section{Unidad de carisma y ministerio jerárquico}

Hemos abordado los conflictos de Monseñor Romero con la Iglesia oficial dentro de la tensa relación que expresa Ignacio en su fórmula "sentir con la Iglesia". Personalmente, Monseñor Romero se sentía obligado, en conciencia, al servicio de los pobres y de su liberación. Esto moldé su rol profético, según el espíritu del evangelio y del Concilio Vaticano II. Con esto cayó en conflicto, no sólo con los ricos y poderosos en El Salvador y de Estados Unidos, sino también con la Iglesia oficial, en Roma. Pero Monseñor Romero, como arzobispo, también fue un "ministro jerárquico" de esa Iglesia. Por lo tanto, experimentó el drama fundamental del "sentir con la Iglesia", en una forma muy personal y existencial. Como "ministro jerárquico" era responsable de la integridad institucional de la Iglesia. Sin embargo, la Iglesia también era para él "el Cuerpo de Cristo viviente en la historia", por lo cual también a ella se aplica la ley fundamental del evangelio: debe estar preparada a perder su vida para ganarla.

Karl Rahner, en su teología de los Ejercicios, trató extensamente el tema de la tensión contenida en la fórmula ignaciana de "sentir con la Iglesia", entre la búsqueda personal de la voluntad de Dios y la Iglesia Institucional. Desde la perspectiva de la filosofía existencial, conceptualizó esta búsqueda como "logica del conocimiento existencial"39. En su artlculo "Lo carismático en la Iglesia", dedujo algunas consecuencias eclesiológicas ${ }^{40}$. Con lo carismático, Rahner no se refiere al movimiento carismático, en el sentido actual, sino a la libre actuación del Espírtu de Dios, incluso fuera de la constitución institucional jerárquica de la Iglesia. Se trata de una contradicción inevitable entre lo carismático y lo institucional, en la Iglesia, "administrable por hombres, computable, que se puede concebir y contener en leyes y normas" "4l. Carisma y ministerio jerárquico están entreverados en una tensión necesaria. Una identificación simplista de ministerio jerárquico y carisma conduciría a una constitución totalitaria de la Iglesia. Los hombres que ocupan los cargos jerárquicos en ella no necesariamente son los máximos representantes carismáticos. En la historia de la Iglesia hay suficientes ejemplos de que los movimientos renovadores "desde abajo", vistos luego como queridos por Dios, tuvieron que imponerse a la resistencia de la jerarquía. Rahner afirma que en la

39. Karl Rahner, Lo dinámico en la Iglesia, Barcelona, 1968, pp 93-181; cfr. Martin Maier, "La theólogie des exercices de Karl Rahner", Recherches de Science Religieuse 79 (1991) 535-560.

40. Karl Rahner, op. cir.. pp. 46-92.

4I. Ibrd., p. 48. 
Iglesia existe "tal dualismo querido por Dios entre carisma y ministerio jerárqui-

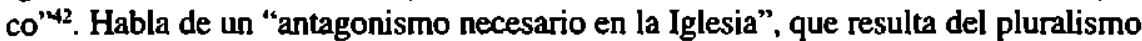
de estímulos: unos desde el ministerio jerárquico, los otros "desde abajo"43.

Monseñor Romero es un ejemplo cabal de esa forma de actuar el Espíritu, en la Iglesia, en tensión, incluso en contradicción con su dirección jerárquica. Como cristiano y obispo, siempre buscó la voluntad de Dios, que para él no se derivaba simplemente de los documentos oficiales o de la tradición eclesial. Monseñor Romero hizo que en su persona resonase y convergiese, de una manera única, carisma y ministerio jerárquico. El hecho de que en la Iglesia haya obispos como Monseñor Romero es una prueba viviente de que en ella el espíritu y el carisma de Jesús están vivos.

Monseñor Romero representa un modelo del ejercicio del ministerio episcopal, en nuestro tiempo. Esa tensión entre lo carismático y lo institucional en la Iglesia marca también el proceso de beatificación de Monseñor Romero, que comenzó en el año de 1990 , y que todavía hoy tratan de frenar los que se oponen a él, en El Salvador y el Vaticano. La misma Iglesia institucional que hace veinticinco años estuvo a un paso de darle una especie de voto de desconfianza, con el nombramiento de un administrador apostólico, lo reconoce ahora como un obispo ejemplar. Se podría considerar corno una forma admirable de auto-corrección, y de ello se deben sacar conclusiones para el actual desempeño de la Iglesia institucional. Debe tomar distancia de la arrogancia y de una falsa autoseguridad, tal como se da todavía hoy, en los dicasterios vaticanos. Debe reconocer su capacidad de enrar y ser más cuidadosa, en cuanto a juzgar y condenar. No se debe apagar el Espíritu en la Iglesia.

Sería contrario a la verdadera intención de Monseñor Romero, en su crítica a la Iglesia, quedarse en una perspectiva internamente eclesial. El centro de su carisma místico lo constituyeron los pobres, en los cuales encontró a Jesucristo. Para él fue muy claro, la espiritualidad cristiana no lo saco del "mundo", sino que lo introdujo más en él. El ser más místico lo llevó a ser más político. Con esto nos ofrece también un modelo para una espiritualidad cristiana adecuada a nuestro tiempo, que se enfrenta a los retos históricos y políticos de Dios, en los signos de los tiempos.

Y recordemos que para el papa Juan XXII, la pobreza mundial fue el más importante signo de los tiempos. Así lo formuló en una alocución radiofónica, el 11 de septiembre de 1962, treinta días antes de la apertura del Concilio Vaticano II: "Frente a los países subdesarrollados la Iglesia es, y quiere ser, la Iglesia de

42. Ibid., p. 78.

43. Cfr. ibid., p. 80. 
todos y en particular de los pobres"44. Su propósito fue hacer del reto de la pobreza el tema central del concilio. Esta petición fue retomada por el cardenal Giacomo Lercaro (1891-1976) de Bologna, en su memorable exposición al concilio, el 6 de diciembre de 1962. Exigió que la problemática de la pobreza se convirtiera en uno de los puntos centrales y decisivos del concilio, incluso en su único tema $a^{45}$.

Como es sabido, este llamado encontró entonces sólo un reducido eco. Sin embargo, en vista de que a nivel mundial existen más de mil millones de personas que viven en absoluta pobreza y que la brecha entre pobres y ricos se profundiza como consecuencia de la globalización económica, recobra una nueva actualidad y necesidad Si la Iglesia no logra, siendo fiel al evangelio, ser consciente de su responsabilidad hacia el mundo para que se realice la justicia, en el sentido de la opción por los pobres, está fallando en su misión de ser servidora de los hombres y, en especial, de los pobres.

Monseñor Romero no ofrece respuestas y soluciones inmediatas a estos problemas. Sin embargo, el testimonio de su vida nos ofrece un modelo actualizado de ser cristiano frente a las necesidades de los hombres. El ligó la eclesiología del pueblo de Dios del concilio a la opción por los pobres, y a la luz del evangelio, vio a los pobres como "pueblo crucificado". Actualmente, no son sólo pueblos crucificados, sino - mirando a África- continentes enteros, donde se refleja la cruz de Cristo. Con ello, Monseñor Romero ha indicado a la Iglesia una orientación decisiva y salvifica para el futuro.

Quizá el núcleo de la mística y de la crítica eclesial de Monseñor Romero podrla resumirse en una variación de una conocida frase de Karl Rahner: "La Iglesia del futuro será mística, pobre y solidaria con los pobres, o no será".

44. Giuseppe Alberigo, "Die Kirche der Armen. Von Johannes XXII. zum Zweiten Vatikanischen Konzil", en Blutende Hoffnung. Homenaje a Gustavo Gutiérrez, publicado por Mariano Delgado, Odilo Noti $\Varangle$ Hermann-Josef Venez, Luzerna, 2000, pp. 70s.

45. Ibid., p. 78. 